\title{
Cost-Effectiveness of Peginterferon Beta-1a and Alemtuzumab in Relapsing-Remitting Multiple Sclerosis
}

\author{
Ankur A. Dashputre, BPharm; Khalid M. Kamal, MPharm, PhD; and Gauri Pawar, MD
}

\begin{abstract}
BACKGROUND: Multiple sclerosis (MS) is a chronic inflammatory disorder of the central nervous system, affecting 2.5 million people globally and 400,000 people in the United States. While no cure exists for MS, the goal is to manage the disease using disease-modifying therapies (DMTs), which have been shown to slow disease progression and prevent relapses. Relapsing-remitting MS (RRMS) is the most common form of MS at the time of diagnosis. Peginterferon beta-1a (PEG) and alemtuzumab (ALT) were recently approved and have demonstrated good clinical outcomes, including reduced relapse rates in clinical trials. High costs associated with these DMTs necessitates cost-effectiveness analyses to understand their overall value in RRMS management.
\end{abstract}

OBJECTIVES: To assess the cost-effectiveness of (a) Model 1: PEG relative to intramuscular interferon beta-1a (IM IFN), subcutaneous interferon beta-1b (SC IFN), glatiramer acetate $20 \mathrm{mg}$ per $\mathrm{mL}$ (GA), fingolimod (FIN), natalizumab (NAT), and dimethyl fumarate (DMF), and (b) Model 2: ALT relative to subcutaneous interferon beta-1a $44 \mu \mathrm{g}$ (IFN beta-1a $44 \mu \mathrm{g}$ ). Both analyses were conducted from a U.S. third-party payer perspective.

METHODS: Two static decision models were used to compare the costeffectiveness of PEG and ALT over a 1-year and a 2-year time horizon, respectively. Model inputs were drug acquisition costs (wholesale acquisition cost from RED BOOK); drug administration and monitoring costs (package inserts and Centers for Medicare \& Medicaid Services 2015 Physician Fee Schedule); relapse rates and relapse rate reduction (clinical trials); and cost of managing relapses (published literature). All costs were adjusted to 2015 U.S. dollars using the medical care component of the Consumer Price Index. Outcomes measured were total cost of therapy per patient, cost per relapse avoided, and incremental cost-effectiveness ratios (ICERs) calculated as cost per relapse avoided. Sensitivity analysis was conducted to test model robustness given the uncertainty of model inputs and study assumptions.

RESULTS: Model 1 results showed that PEG dominated IM IFN and GA, compared with SC IFN; PEG had an ICER of $\$ 1,978,000$ per relapse avoided. Compared with FIN, NAT, and DMF, PEG was less expensive and less effective. Model 2 showed that ALT had an ICER of $\$ 25,276$ per relapse avoided relative to IFN beta-1a $44 \mu \mathrm{g}$.

CONCLUSIONS: In patients with RRMS, PEG is a viable alternative when compared with the DMTs in our model. Deciding whether to choose PEG over other DMTs would depend on multiple factors. On the other hand, ALT had an ICER of $\$ 25,276$ cost per relapse avoided relative to IFN beta-1a $44 \mu \mathrm{g}$. The study results will assist payers in evaluating different medication choices for effective therapy.

J Manag Care Spec Pharm. 2017;23(6):666-76

Copyright $\odot 2017$, Academy of Managed Care Pharmacy. All rights reserved.

\section{What is already known about this subject}

Peginterferon beta-la (PEG) and alemtuzumab (ALT) were approved by the U.S. Food and Drug Administration in 2014. In previous studies conducted over a 10-year time frame, PEG has been shown to dominate subcutaneous interferon (IFN) beta-la $44 \mu \mathrm{g}$ and glatiramer acetate (GA).

In the only previous U.S. study, which was conducted over a 2-year time frame, ALT had an incremental cost-effectiveness ratio (ICER) of $\$ 43,826$ per quality-adjusted life-years (QALY) relative to subcutaneous IFN beta-1a $44 \mu \mathrm{g}$.

\section{What this study adds}

Static decision models were used to compare the cost-effectiveness of PEG and ALT over 1-year and 2-year time frames, respectively, in patients with relapsing-remitting multiple sclerosis.

ICER values were measured as cost per relapse avoided as compared with cost per QALY, which was reported in earlier studies. This study included oral and injectable disease-modifying therapies and found that PEG dominated intramuscular IFN beta-la and GA; was more expensive but had comparable effectiveness when compared with subcutaneous IFN beta-1b; and was less expensive and less effective when compared with natalizumab, fingolimod, and dimethyl fumarate.

$\mathrm{M}$ ultiple sclerosis (MS) is a progressive, debilitating autoimmune disorder that affects the central nervous system. It is characterized by the destruction of the myelin sheath and inhibition of nerve impulses, eventually resulting in loss of motor function and a high level of disability. In addition to being associated with impaired mobility, MS affects quality of life, causing fatigue, pain, swallowing and breathing problems, cognitive impairment, hearing and vision problems, and sexual dysfunction. The Multiple Sclerosis Foundation reports an estimated prevalence of 400,000 people in the United States, with over 2.5 million people affected globally. ${ }^{1}$ MS is typically diagnosed between the ages of 20-40 years, and women are twice as likely as men to be affected by the disease. ${ }^{1}$ The National Multiple Sclerosis Society reports an estimated total cost of $\$ 28$ billion annually for individuals with MS in the United States, with an average annual cost of $\$ 69,000$ per person, including direct and indirect costs. ${ }^{2}$ 
Based on the clinical course, MS can be classified into 3 subtypes: relapsing-remitting MS (RRMS), secondary-progressive MS (SPMS), and primary-progressive MS (PPMS). ${ }^{3}$ RRMS is the most common disease course and is seen in $85 \%$ of all cases at initial diagnosis. RRMS is characterized by clearly defined relapses followed by remissions, during which there is no apparent disease progression. ${ }^{3}$ Individuals diagnosed with RRMS transition to SPMS, with 50\% transitioning within 10 years and $90 \%$ transitioning within 25 years of RRMS diagnosis. ${ }^{3}$ PPMS is seen in $15 \%$ of individuals diagnosed with MS. ${ }^{3}$

Disease-modifying therapies (DMTs) are used to manage MS to modify the disease course, reduce the number of relapses, and improve patient quality of life. Over the years, a number of DMTs have been approved by the U.S. Food and Drug Administration (FDA) for the management of MS. These approved DMTs include 4 beta interferon products, branded and generic forms of glatiramer acetate, teriflunomide, fingolimod, dimethyl fumarate, mitoxantrone, and natalizumab. In 2014, peginterferon beta-la (Plegridy), a pegylated form of beta interferon, and alemtuzumab (Lemtrada), a CD52-directed cytolytic antibody were approved by the FDA.

Compared with earlier beta interferons, peginterferon betala has a lower dosing frequency, with 26 doses per year, and alemtuzumab has a dosing frequency split over 2 years (year $1=5$ doses on consecutive days; year $2=3$ doses on consecutive days) and is reserved for patients who have inadequately responded to 2 or more earlier DMTs. Phase 3 clinical trials of peginterferon beta-la (ADVANCE) and alemtuzumab (CARE-MS I and II) have shown significant reduction in annual relapse rates in patients using these DMTs (36\% reduction vs. placebo and 49\%-55\% reduction vs. subcutaneous interferon beta-la, respectively). ${ }^{4-6}$ Although these treatments have demonstrated better efficacy rates and offer new treatment alternatives to patients with MS, the estimated costs are $\$ 65,442$ for 1 year of peginterferon beta-la treatment and $\$ 158,000$ for 2 years of alemtuzumab treatment. Given the high cost of therapy, it is important to evaluate the value of these new treatments with respect to their outcomes, compared with existing DMTs.

Several studies have assessed the cost-effectiveness of these new treatments. Studies on peginterferon beta-la have been conducted in the United States, Italy, Ireland, and Scotland and have compared peginterferon beta-la to multiple comparators over 10 years to lifetime analytic time frames using societal and payer perspectives. ${ }^{7-11}$ Studies on alemtuzumab have been conducted in the Unites States, Ireland, and the United Kingdom using societal and payer perspectives and have used 2- to 10-year analytic time frames. ${ }^{12-14}$ Both U.S.-based studies on peginteferon beta-la used a payer perspective and an analytical time frame of 10 years. ${ }^{7.8}$ The U.S.-based alemtuzumab study used a 2-year time frame and was conducted from a societal perspective..$^{14}$ Although several studies on the newly approved DMTs have been conducted in the United States, no study has looked at their cost-effectiveness from a payer perspective over a shorter time horizon.

The objectives of this study were (a) to estimate the incremental cost-effectiveness of peginteferon beta-la (PEG) relative to intramuscular interferon (IM IFN) beta-la, subcutaneous interferon (SC IFN) beta-1b, glatiramer acetate $20 \mathrm{mg}$ per $\mathrm{mL}$ (GA), fingolimod (FIN), natalizumab (NAT), and dimethyl fumarate (DMF) and (b) to estimate the incremental costeffectiveness of alemtuzumab (ALT) relative to subcutaneous interferon beta-la $44 \mu \mathrm{g}$ (IFN beta-la $44 \mu \mathrm{g}$ ).

\section{Methods}

\section{Model Characteristics}

Model Design. Two separate static decision models were developed using Microsoft Excel (Microsoft Corp, Redmond, WA) to evaluate the cost-effectiveness of PEG and ALT in a hypothetical RRMS population. Static models were used because the evaluation involved shorter time horizons. Also, since RRMS was being studied, and its transition to SPMS occurs over 10 years, a static model with robust data from randomized controlled trials was sufficient to demonstrate the costeffectiveness of these treatments. ${ }^{3}$ Dynamic models, on the other hand, need time-dependent transition probabilities and long-term outcomes and invariably include assumptions that may introduce uncertainty in the models. For this study, Model 1 compared PEG with multiple comparators-IM IFN, SC IFN, GA, FIN, NAT, and DMF-and Model 2 compared ALT with IFN beta-la $44 \mu \mathrm{g}$.

Patient Population and Perspective. The hypothetical patient population for both models were RRMS patients, and demographic and clinical characteristics were based on clinical trial data of the 2 treatments.

Both models were analyzed from a U.S. third-party payer perspective. As a result, only direct costs such as drug acquisition costs, drug administration and monitoring costs, health care provider visit costs, and relapse treatment costs were included in the analysis.

Analytical Time Frame. Model 1 (PEG) and Model 2 (ALT) were analyzed over a 1-year and 2-year time horizon, respectively, from the point of initiation of therapy, and incremental cost-effectiveness ratios (ICERs) of the treatments were assessed. Different time frames were selected based on the frequency of drug administration. In Model 1, PEG had a time frame of 1 year, since it is administered once every 14 days, while a longer time frame was selected for ALT, in Model 2, since ALT is prescribed over 2 treatment courses, which are 12 months apart. Short time frames were chosen because (a) they reflect the length of phase 3 clinical trials and outcomes assessed in these clinical trials, and (b) most U.S. third-party payers prefer shorter time periods (1-3 years) when conducting economic analyses. ${ }^{4-6,15-22}$ 
TABLE 1 Number of Relapses Avoided per Patient over Respective Horizons for Models 1 and 2

Model 1: PEG

\begin{tabular}{l|c|c|c|c|c}
\hline DMT & $\begin{array}{c}\text { Number of Relapses } \\
\text { (Placebo) }\end{array}$ & $\begin{array}{c}\text { Number of Patients } \\
\text { (Placebo) }\end{array}$ & $\begin{array}{c}\text { Relative Relapse Rate } \\
\text { Reduction (\%) }\end{array}$ & $\begin{array}{c}\text { Number of Relapses } \\
\text { Avoided per Patient }\end{array}$ & $\begin{array}{c}\text { Number of Relapses } \\
\text { per Patient }\end{array}$ \\
\hline PEG $^{5}$ & 0.40 & 500 & 36 & 0.20 & 0.35 \\
\hline IM IFN beta-1a17 & 0.82 & 143 & 18 & 0.10 & 0.45 \\
\hline SC IFN beta-1b18 & 1.27 & 123 & 34 & 0.19 & 0.36 \\
\hline GA $^{19}$ & 0.84 & 126 & 29 & 0.30 & 0.39 \\
\hline FIN $^{20}$ & 0.40 & 418 & 54 & 0.36 & 0.25 \\
\hline NAT $^{21}$ & 0.73 & 315 & 65 & 0.19 & 0.29 \\
\hline DMF2 $^{22}$ & 0.36 & 408 & 53 & & 0.26 \\
\hline
\end{tabular}

Model 2: ALT

\begin{tabular}{l|c|c|c|c|c}
\hline DMT & $\begin{array}{c}\text { Number of Relapses } \\
\text { at Baseline }\end{array}$ & Number of Patients & $\begin{array}{c}\text { Number of Relapses } \\
\text { at 2 Years }\end{array}$ & $\begin{array}{c}\text { Relative Relapse Rate } \\
\text { Reduction (\%) }\end{array}$ & $\begin{array}{c}\text { Number of Relapses } \\
\text { Avoided per Patient }\end{array}$ \\
\hline ALT6 & 1.7 & 426 & 0.52 & 69.41 & \\
\hline IFN beta-la 44 $\mu \mathrm{g}^{23}$ & 1.5 & 202 & 1.04 & 30.67 & \\
\hline
\end{tabular}

$A L T=$ alemtuzumab; DMF = dimethyl fumarate; DMT = disease-modifying therapy; FIN = fingolimod; GA = glatiramer acetate; IFN=interferon; IM = intramuscular; $N A T=$ natalizumab; $P E G=$ peginterferon beta-1a; $S C=$ subcutaneous

Outcome Measures. Outcomes of interest for both models were total cost of therapy per patient, cost per relapse avoided, and ICERs. Incremental ratios were calculated as additional cost per patient to avoid 1 relapse. The ICERs were calculated as follows:

ICER $=\operatorname{Cost}_{A}-\operatorname{Cost}_{B} \div$ Number of relapse avoided per patient $_{A}-$ Number of relapse avoided per patient $_{B}$

For Model 1, A=PEG; B = IM IFN, SC IFN, GA, FIN, NAT, and DMF. For Model 2, A=ALT; B = IFN beta-la $44 \mu \mathrm{g}$

Sensitivity Analysis. Since this study involved estimations and there were uncertainty in some variables, univariate sensitivity analyses were conducted to determine the effect of varying the model inputs on the cost-effectiveness of PEG and ALT. Drug acquisition costs, cost of relapse management, and number of relapses per patient before treatment were varied over a range of estimates $( \pm 20 \%)$ to test the robustness of the results. The literature supports the use of $\pm 20 \%-25 \%$ as variations in the base case wherever the range was not available. ${ }^{15,23-25}$

\section{Efficacy Input}

Annualized relapse rate (except for IFN beta-la $44 \mu \mathrm{g}$, mean number of relapses over 2 years) was used as the efficacy input in the models, since it was commonly reported in the phase 3 clinical trials of the DMTs. ${ }^{4,5,16-22}$ These relapse rates were used to calculate the number of relapses per patient and number of relapses avoided per patient after treatment with DMTs over their respective time horizons. The model calculations are shown as follows.

\section{Model 1 (PEG)}

A weighted average of annualized relapses was calculated for patients in the placebo group (untreated patients) using published phase 3 clinical trial data for the DMTs. The relative reduction in relapse rates was taken from the phase 3 clinical trials (PEG, 36\%, IM IFN beta-la 18\%, ${ }^{16}$ SC IFN beta-1b 34\%, ${ }^{17}$ GA $29 \%,{ }^{18}$ FIN 54\%, ${ }^{19}$ NAT $65 \%,{ }^{20}$ and DMF $53 \%{ }^{21}$ ). The number of relapses avoided per patient was calculated as the product of weighted average of annualized relapse rate and relative rate of reduction for each DMT. The number of relapses per patient was calculated by subtracting number of relapses avoided per patient from the weighted average of annualized relapse rate:

Weighted annualized relapse rate $=\Sigma($ Annual relapses $\times$ Number of patients in placebo group) $\div \Sigma$ Number of patients in placebo group

Number of relapses avoided/patient $=$ Weighted annualized relapse rate $\times$ Relative rate of reduction

Number of relapses/patient $=$ Weighted annualized relapse rate-

Model 2 (ALT)

Number of relapses avoided perpatient

Since Model 2 had a 2-year time frame, the following formula was used to first calculate the relative reduction in relapse, and then the number of relapse avoided per patient was calculated.

Relative reduction in relapse $=($ Number of relapses at the end of 2 years of clinical trial Number of relapses at baseline) $\times 100 \div$ Number of relapses at baseline 
TABLE 2 DMT Dosing and Acquisition Cost

\begin{tabular}{|c|c|c|c|c|c|}
\hline DMT & Dose, Frequency, Route & Doses per Pack & Packs per Year & $\begin{array}{l}\text { Wholesale Acquisition } \\
\text { Price per Package } \\
(2015 \text { U.S. \$) }\end{array}$ & $\begin{array}{l}\text { Wholesale Acquisition } \\
\text { Price per Year } \\
\text { (2015 U.S. \$) }\end{array}$ \\
\hline \multicolumn{6}{|l|}{ Model 1: PEG } \\
\hline $\mathrm{PEG}^{24}$ & $\begin{array}{l}125 \mu \mathrm{g} \\
\text { Every } 14 \text { days } \\
\text { Subcutaneous }\end{array}$ & 2 & 13 & $5,034.00$ & $65,442.00$ \\
\hline IM IFN beta-la ${ }^{25}$ & $\begin{array}{l}30 \mu \mathrm{g} \\
\text { Once a week } \\
\text { Intramuscular }\end{array}$ & 4 & 13 & $5,034.00$ & $5,034.00$ \\
\hline SC IFN beta-1b26 & $\begin{array}{l}0.25 \mathrm{mg} \\
\text { Every other day } \\
\text { Subcutaneous }\end{array}$ & 15 & 12.2 & $3,740.75$ & $45,637.00$ \\
\hline $\mathrm{GA}^{27}$ & $\begin{array}{l}20 \mathrm{mg} / \mathrm{mL} \\
\text { Every day } \\
\text { Subcutaneous }\end{array}$ & 30 & 12.2 & $6,110.50$ & $6,110.50$ \\
\hline FIN $^{28}$ & $\begin{array}{l}0.5 \mathrm{mg} \\
\text { Every day } \\
\text { Oral }\end{array}$ & 30 & 12.2 & $5,831.22$ & $5,831.22$ \\
\hline $\mathrm{NAT}^{29}$ & $\begin{array}{l}300 \mathrm{mg} \\
\text { Every } 4 \text { weeks } \\
\text { Intravenous infusion }\end{array}$ & 1 & 13 & $4,960.00$ & $64,480.00$ \\
\hline \multirow[t]{2}{*}{$\overline{\mathrm{DMF}^{30}}$} & $\begin{array}{l}\text { SD: } 120 \mathrm{mg} \\
\text { Twice daily for } 7 \text { days }\end{array}$ & & 12.9 & SD: $1,274.00$ & $66,248.00$ \\
\hline & $\begin{array}{l}\text { MD: } 240 \mathrm{mg} \\
\text { Twice daily after } 7 \text { days } \\
\text { Oral }\end{array}$ & MD: 60 & & MD: $5,460.00$ & \\
\hline \multicolumn{6}{|l|}{ Model 2: ALT } \\
\hline $\mathrm{ALT}^{31}$ & $\begin{array}{l}\text { Year 1:12 mg/day } \\
5 \text { consecutive days } \\
\text { Year 2:12 mg/day } \\
3 \text { consecutive days } \\
\text { Intravenous infusion }\end{array}$ & 1 & $\begin{array}{l}\text { Year 1: } 5 \\
\text { Year 2: } 3\end{array}$ & $19,750.00$ & $\begin{array}{l}\text { Year 1: } 98,750.00 \\
\text { Year 2: } 59,250.00\end{array}$ \\
\hline IFN beta-la $44 \mu g^{32}$ & $\begin{array}{l}44 \mu g \\
3 \text { times per week } \\
\text { Subcutaneous }\end{array}$ & 12 & 13 & $5,433.70$ & $70,638.00$ \\
\hline
\end{tabular}

$A L T=$ alemtuzumab; DMF = dimethyl fumarate; DMT = disease-modifying therapy; FIN = fingolimod; GA = glatiramer acetate; IFN=interferon; IM =intramuscular; $M D=$ maintenance dose; $N A T=$ natalizumab; $P E G=$ peginterferon beta- $1 a ; S C=$ subcutaneous; $S D=$ starting dose .

The number of relapses avoided was calculated as a product of relative reduction in relapse and number of relapses at baseline for ALT and IFN beta-la $44 \mu \mathrm{g}$. Baseline relapses were taken from phase 3 clinical trials., 52 The number of relapses avoided per patient for models 1 and 2 are presented in Table 1.

\section{Cost Input}

Drug Acquisition Costs. Drug acquisition costs were calculated using the wholesale acquisition cost from the 2015 RED BOOK. Dosage information from published FDA package inserts and number of doses per package from RED BOOK were used to calculate the number of packages per year per patient. For both models, the drug acquisition cost was calculated as the product of the monthly cost of drug acquisition and the number of packages required per year over the respective time horizon. Both models did not take into account product rebates, discounts, copays, or coinsurance. DMT dose, frequency, route of administration, and acquisition cost are presented in Table 2.

Drug Administration and Monitoring. The drug administration and monitoring schedules used in both models were taken from the DMT package inserts.

\section{Model 1 (PEG)}

Each DMT has a different route of administration, so the cost of administration was accounted for in the model. Unlike PEG (subcutaneous), IFN beta products (subcutaneous, intramuscular), GA (subcutaneous), FIN (oral), and DMF (oral), NAT is an intravenous infusion and is administered over a 1-hour period under the supervision of a health care provider, followed by an observation period of 1 hour. ${ }^{26-32}$ As such, our analysis included administration costs for NAT. 
TABLE 3 DMT Administration and Monitoring Frequency and Health Care Provider Utilization for Models 1 and 2

\begin{tabular}{|c|c|c|c|c|c|c|c|c|c|}
\hline \multicolumn{8}{|c|}{ Model 1: PEG } & \multicolumn{2}{|c|}{ Model 2: ALT } \\
\hline & PEG & $\begin{array}{l}\text { IM IFN } \\
\text { beta-la }\end{array}$ & $\begin{array}{l}\text { SC IFN } \\
\text { beta-lb }\end{array}$ & GA & FIN & NAT & DMF & ALT & $\begin{array}{c}\text { IFN beta-la } \\
44 \mu \mathrm{g}\end{array}$ \\
\hline \multicolumn{10}{|l|}{ Drug administration } \\
\hline Frequency & 26 & 52 & 183 & 365 & 365 & 13 & 730 & 8 & 312 \\
\hline \multicolumn{10}{|l|}{ Monitoring } \\
\hline Complete blood count ${ }^{24-30}$ & 3 & 2 & 3 & 1 & 2 & 1 & 3 & 25 & 6 \\
\hline Liver function test $24-29$ & 3 & 2 & 3 & 1 & 1 & 1 & 0 & N/A & 6 \\
\hline $\begin{array}{l}\text { Magnetic resonance } \\
\text { imaging } 29\end{array}$ & 0 & 0 & 0 & 0 & 0 & 1 & 0 & 9 & N/A \\
\hline Electrocardiogram $^{28}$ & 0 & 0 & 0 & 0 & 2 & 0 & 0 & 25 & N/A \\
\hline Macular edema testing 28 & 0 & 0 & 0 & 0 & 2 & 0 & 0 & 25 & N/A \\
\hline Thyroid function test ${ }^{25}$ & 0 & 2 & 0 & 0 & 0 & 0 & 0 & 9 & N/A \\
\hline Serum creatinine level & N/A & N/A & N/A & N/A & N/A & N/A & N/A & 25 & N/A \\
\hline Urineanalysis & N/A & N/A & N/A & N/A & N/A & N/A & N/A & 25 & N/A \\
\hline Skin test for melanoma & N/A & N/A & N/A & $\mathrm{N} / \mathrm{A}$ & N/A & N/A & N/A & 3 & N/A \\
\hline \multicolumn{10}{|l|}{ Health care provider visit } \\
\hline Neurologist $^{33}$ & 3 & 3 & 3 & 3 & 3 & 4 & 3 & 7 & 6 \\
\hline
\end{tabular}

ALT = alemtuzumab; DMF = dimethyl fumarate; DMT = disease-modifying therapy; FIN = fingolimod; GA = glatiramer acetate; IFN = interferon; IM=intramuscular; N/A = not applicable; NAT = natalizumab; PEG= peginterferon beta-1a; SC=subcutaneous.

Laboratory tests and imaging procedures, such as magnetic resonance imaging (MRI) during DMT therapy, were taken from package inserts. For those DMTs with no explicit requirements for complete blood count $(\mathrm{CBC})$ and liver function test (LFT), it was assumed that each of these tests were conducted at least once before the initiation of therapy. For PEG, since the frequency of CBC and LFT was not stated in the package insert, both tests were assumed to have been provided 3 times in 1 year. The model assumed 1 MRI for NAT conducted before initiation of therapy as per the recommendation in the NAT package insert. ${ }^{31}$ The model assumed 3 neurologist visits for all drugs (except NAT) based on an MS health care utilization study that reported a mean of 3.4 visits per patient for 12 months. ${ }^{33}$ The model also assumed an extra visit for patients on NAT, since the drug is distributed through a restricted program, with a recommendation that prescribers evaluate patients after 3 and 6 months of initiation of therapy and then 6 months after that. ${ }^{31}$

\section{Model 2 (ALT)}

ALT is an intravenous infusion that needs to be administered over 4 hours under the supervision of a health care provider, followed by a 2-hour observation period. ${ }^{34}$ IFN beta-la $44 \mu \mathrm{g}$ is self-administered subcutaneously and does not include a cost for administration..$^{35}$ Laboratory tests were taken from package inserts. Three neurologist visits were assumed per year for IFN beta-la $44 \mu \mathrm{g}$, and 1 extra visit was assumed for ALT because of restricted prescribing. ${ }^{34,35}$ The model assumed an extra visit for patients on ALT, since it is distributed through a restricted program in which prescribers are advised to assess patients before baseline infusion, at 6 months after first infusion, and every 6 months thereafter. ${ }^{36}$

Neither model accounted for costs associated with serious adverse events. The comparators-NAT, FIN, and DMF-are associated with serious adverse events, such as progressive multifocal leukoencephalopathy (PML). However, the occurrence of PML is 1 in 1,000, with a mean occurrence of 17.9 months in patients on NAT and 2.5 years and 4 years for patients on FIN and DMF, respectively. ${ }^{30,32,37}$ Model 1 (PEG) had a 1-year horizon, so it was assumed that there would be no expected incidence of PML within the analytical time frame. For Model 2, ALT is associated with immune thrombocytopenia (ITP) and antiglomerular basement membrane disease (AGBMD). However, these adverse events were not included in the model, since their occurrence is low $(<1 \%-1 \%){ }^{34}$

Relapse Management Cost. Cost for relapse management was acquired from Bozkaya et al. (2015). ${ }^{7}$ The cost per relapse was calculated as the product of relapse per patient and cost of relapse management.

The costs for laboratory and monitoring tests was extracted from the Centers for Medicare \& Medicaid Services 2015 Physician Fee Schedule using the Current Procedural Terminology codes for each test. ${ }^{38}$ Costs for neurologist visits were taken from the U.S. Bureau of Labor Statistics. ${ }^{39}$ DMT administration and monitoring frequency and health care provider utilization for both models are presented in Table 3. All costs were adjusted to 2015 U.S. dollars using the medical care component of the Consumer Price Index. ${ }^{40}$ 
TABLE 4 Total Cost per Patient, Relapses Avoided, Cost per Relapse Avoided and ICERs for Models 1 and 2

\begin{tabular}{|c|c|c|c|c|c|c|c|c|c|}
\hline \multicolumn{8}{|c|}{ Model 1: PEG } & \multicolumn{2}{|c|}{ Model: 2 ALT } \\
\hline & PEG & $\begin{array}{l}\text { IM IFN } \\
\text { beta-la }\end{array}$ & $\begin{array}{l}\text { SC IFN } \\
\text { beta-1b }\end{array}$ & GA & FIN & NAT & DMF & ALT & $\begin{array}{c}\text { IFN } \\
\text { beta-la } 44 \mu \mathrm{g}\end{array}$ \\
\hline DMT cost $(\$)$ & 65,442 & 65,442 & 45,637 & 74,548 & 71,141 & 64,480 & 66,248 & 158,000 & 141,276 \\
\hline $\begin{array}{l}\text { Administration + monitoring } \\
+ \text { utilization cost }(\$)\end{array}$ & 340 & 364 & 340 & 296 & 802 & 2,331 & 307 & 3,438 & 810 \\
\hline Treatment of relapses $(\$)^{a}$ & 776 & 998 & 798 & 865 & 554 & 421 & 576 & 1,153 & 2,306 \\
\hline Total cost (\$) & 66,558 & 66,804 & 46,775 & 75,710 & 72,761 & 67,232 & 67,131 & 162,591 & 144,392 \\
\hline Relapse avoided per patient & 0.20 & 0.10 & 0.19 & 0.16 & 0.30 & 0.36 & 0.29 & 1.18 & 0.46 \\
\hline Cost per relapse avoided $(\$)$ & 332,790 & 668,040 & 246,184 & 473,188 & 242,537 & 186,756 & 231,486 & 137,789 & 313,896 \\
\hline $\begin{array}{l}\text { ICER }(\$)^{b} \\
\text { Cost }_{A}-\text { Cost }_{B} \div \text { Number } \\
\text { of relapses avoided } \\
\text { Number of relapses avoided } \\
\text { Numb }\end{array}$ & - & $\begin{array}{c}\mathrm{PEG} \\
\text { dominated }\end{array}$ & $\begin{array}{l}\text { PEG vs. SC } \\
\text { IFN beta-lb: } \\
\$ 1,978,000\end{array}$ & $\begin{array}{c}\text { PEG } \\
\text { dominated }\end{array}$ & $\begin{array}{c}\text { FIN vs. PEG: } \\
62,030^{c}\end{array}$ & $\begin{array}{c}\text { NAT vs. PEG: } \\
4,213^{c}\end{array}$ & $\begin{array}{c}\text { DMF vs. PEG: } \\
6,367^{c}\end{array}$ & - & $\begin{array}{c}\text { ALT vs. IFN } \\
\text { beta-la } 44 \mu \mathrm{g}: \\
\$ 25,276\end{array}$ \\
\hline
\end{tabular}

Note: All costs are reported per person in 2015 U.S. dollars.

aCost for relapse treatment was calculated as a product of number of relapses elapses after DMT treatment and cost of treating 1 relapse. Cost of treating relapse was extracted from literature (inflated to 2015 dollars: $\$ 2,217$ ). ${ }^{7}$

${ }^{b}$ Cost $_{A}$ and Cost $_{B}$ for Model 1: A=PEG; B =IM IFN, SC IFN, GA, FIN, NAT, and DMF; for Model 2, A=ALT; B=IFN beta-1a 44 $\mu$ g.

CICERs for FIN, NAT, and DMF are compared with PEG, since these 3 DMTs cost more and were more effective than PEG.

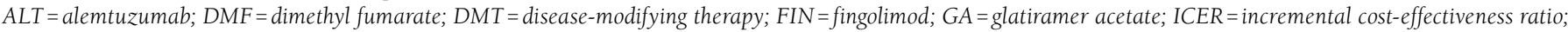
IFN = interferon; IM = intramuscular; NAT = natalizumab; PEG=peginterferon beta-1a; SC = subcutaneous.

\section{Model Assumptions}

Published real-world adherence data for PEG and ALT were not available at the time of model development. Although adherence rates for comparators were available, adherence was assumed to be $100 \%$ to provide a fair comparison and avoid preference of any DMT. Patients were assumed to be maintained on the assigned DMTs throughout the duration of the model. Clinical inputs (annualized relapse rates and relative relapse rate reduction) taken from published phase 3 clinical trials were assumed to be highly reliable and valid. Both models had a short analytic frame, so it was assumed that the disease condition of the patient remained the same and that the patient did not transition into a higher level of disease severity. The cost for a neurologist visit was assumed to be the same for each visit, and the model did not account for any potential differences in the intensity of the visits. The number of CBC and LFT tests conducted for PEG per year was assumed to be 3, and this was based on expert opinion. An extra visit was assumed for patients on NAT and ALT because of their restricted prescribing. ${ }^{31,36}$

\section{Results}

\section{Base-Case Analysis}

For a hypothetical RRMS population, Table 4 describes the total cost per patient, number of relapses avoided per patient, cost per relapse avoided per patient, and ICERs for each DMT analyzed in the 2 models.

\section{Model 1 (PEG)}

Total cost of therapy per person for 1 year was $\$ 66,558$ for PEG, which was lower compared with all DMTs except SC IFN beta-1b $(\$ 46,775)$. PEG avoided a greater number of relapses (0.20) compared with IM IFN beta-la (0.10) and GA (0.16) but avoided fewer relapses compared with FIN (0.30), NAT (0.36), and DMF (0.29). For the number of relapses avoided, SC IFN beta-1b was almost comparable to PEG (PEG 0.20 vs. SC IFN beta-1b 0.19). The cost per relapse avoided was lowest for NAT $(\$ 186,756)$, followed by DMF $(\$ 231,486)$, FIN $(\$ 242,537)$, and SC IFN beta-1b $(\$ 246,184)$. PEG $(\$ 332,790)$ fared better than GA $(\$ 473,188)$ and IM IFN beta-la $(\$ 668,040)$ only. The ICER values show that PEG dominated (less costly and more effective) IM IFN and GA. PEG had an ICER of $\$ 1,978,000$ per relapse avoided compared with SC IFN beta-lb. This might be due to the comparable efficacy between the 2 comparators. However, when compared with NAT, DMF, and FIN, PEG was less costly and less effective. The ICERs for FIN, NAT, and DMF, compared with PEG, were $\$ 62,040, \$ 4,213$, and $\$ 6,267$ per relapse avoided, respectively (Table 4).

\section{Model 2 (ALT)}

Total cost of therapy per patient for ALT was higher than IFN beta-la $44 \mu \mathrm{g}(\$ 162,591$ vs. $\$ 144,392)$. However, the number of relapses avoided was higher for ALT compared with IFN betala $44 \mu \mathrm{g}$ (1.18 vs. 0.46). Thus, the cost per relapse avoided per patient was significantly lower for ALT compared with IFN betala $44 \mu \mathrm{g}(\$ 137,789$ vs. $\$ 313,896)$. ALT had an ICER of $\$ 25,276$ per relapse avoided compared with IFN beta-la $44 \mu \mathrm{g}$ (Table 4). 
TABLE 5 Univariate Sensitivity Analysis of ICERs (Cost per Relapse Avoided) for Models 1 and 2

\begin{tabular}{|c|c|c|c|c|c|c|}
\hline & \multicolumn{6}{|c|}{ Input Variable } \\
\hline & \multicolumn{2}{|c|}{ Drug Acquisition Cost } & \multicolumn{2}{|c|}{ Number of Relapses Before Treatment } & \multicolumn{2}{|c|}{ Cost for Relapse Treatment } \\
\hline & $(+)$ & $(-)$ & $(+)$ & $(-)$ & $(+)$ & $(-)$ \\
\hline \multicolumn{7}{|c|}{ Model 1: PEG ICERS } \\
\hline IM IFN beta-la & PEG dominated & PEG dominated & PEG dominated & PEG dominated & PEG dominated & PEG dominated \\
\hline SC IFN beta-lb & $\begin{array}{c}\text { PEG vs. SC IFN } \\
\text { beta-lb: } \$ 2,374,400\end{array}$ & $\begin{array}{c}\text { PEG vs. SC IFN } \\
\text { beta-lb: } \$ 1,582,200\end{array}$ & $\begin{array}{c}\text { PEG vs. SC IFN } \\
\text { beta-1b: } \$ 1,976,100\end{array}$ & $\begin{array}{c}\text { PEG vs. SC IFN } \\
\text { beta-lb: } \$ 1,978,300\end{array}$ & $\begin{array}{c}\text { PEG vs. SC IFN } \\
\text { beta-1b: } \$ 1,977,800\end{array}$ & $\begin{array}{c}\text { PEG vs. SC IFN } \\
\text { beta-1b: } \$ 1,978,800\end{array}$ \\
\hline $\mathrm{GA}$ & PEG dominated & PEG dominated & PEG dominated & PEG dominated & PEG dominated & PEG dominated \\
\hline FIN & $\begin{array}{c}\text { FIN vs. PEG: } \\
\$ 70,790\end{array}$ & $\begin{array}{c}\text { FIN vs. PEG: } \\
\$ 47,990\end{array}$ & $\begin{array}{l}\text { FIN vs. PEG: } \\
\$ 49,308\end{array}$ & $\begin{array}{c}\text { FIN vs. PEG: } \\
\$ 74,788\end{array}$ & $\begin{array}{l}\text { FIN vs. PEG: } \\
\$ 58,950\end{array}$ & $\begin{array}{c}\text { FIN vs. PEG: } \\
\$ 59,830\end{array}$ \\
\hline NAT & $\begin{array}{c}\text { NAT vs. PEG: } \\
\$ 3,015\end{array}$ & $\begin{array}{c}\text { NAT vs. PEG: } \\
\$ 5,415\end{array}$ & $\begin{array}{c}\text { NAT vs. PEG: } \\
\$ 3,200\end{array}$ & $\begin{array}{c}\text { NAT vs. PEG: } \\
\$ 5,700\end{array}$ & $\begin{array}{c}\text { NAT vs. PEG: } \\
\$ 3,375\end{array}$ & $\begin{array}{c}\text { NAT vs. PEG: } \\
\$ 4,656\end{array}$ \\
\hline$\overline{\mathrm{DMF}}$ & $\begin{array}{c}\text { DMF vs. PEG: } \\
\$ 8,160\end{array}$ & $\begin{array}{c}\text { DMF vs. PEG: } \\
\$ 4,560\end{array}$ & $\begin{array}{c}\text { DMF vs. PEG: } \\
\$ 4,809\end{array}$ & $\begin{array}{c}\text { DMF vs. PEG: } \\
\$ 8,814\end{array}$ & $\begin{array}{c}\text { DMF vs. PEG: } \\
\$ 5,922\end{array}$ & $\begin{array}{c}\text { DMF vs. PEG: } \\
\$ 6,811\end{array}$ \\
\hline \multicolumn{7}{|c|}{ Model 2: ALT ICERs } \\
\hline IFN beta-la $44 \mu \mathrm{g}$ & \begin{tabular}{|c|} 
ALT vs. IFN beta-la \\
$44 \mu \mathrm{g}: \$ 29,922$
\end{tabular} & $\begin{array}{c}\text { ALT vs. IFN beta-la } \\
44 \mu \mathrm{g}: \$ 20,631\end{array}$ & $\begin{array}{c}\text { ALT vs. IFN beta-la } \\
44 \mu \mathrm{g}: \$ 23,384\end{array}$ & $\begin{array}{c}\text { ALT vs. IFN beta-la } \\
44 \mu \mathrm{g}: \$ 32,356\end{array}$ & \begin{tabular}{|c} 
ALT vs. IFN beta-la \\
$44 \mu \mathrm{g}: \$ 24,957$
\end{tabular} & $\begin{array}{c}\text { ALT vs. IFN beta-la } \\
44 \mu \mathrm{g}: \$ 25,576\end{array}$ \\
\hline
\end{tabular}

\section{Sensitivity Analysis}

For Model 1, drug acquisition costs, cost of relapse management, and average number of relapses per patient before treatment were varied by $\pm 20 \%$ of the base-case estimates (Table 5 ). Sensitivity analysis results demonstrated that PEG dominated IM IFN and GA after varying all 3 parameters. On varying drug acquisition cost, PEG had an ICER that ranged from $\$ 1,582,200$ to $\$ 2,374,400$, compared with SC IFN. When NAT, FIN, and DMF were compared with PEG, NAT had the lowest ICERs, followed by DMF and FIN. Average number of relapses per patient before treatment and cost of relapse management when increased by $20 \%$ of base-case results showed better ICERs (lower) compared with decreasing these inputs by $20 \%$.

As with Model 1, base-case estimates were varied by $\pm 20 \%$ in Model 2 (Table 5). Results showed that ALT had an ICER of $\$ 20,631$ (-20\% base case) and $\$ 29,922$ ( $+20 \%$ base case) compared with IFN beta-la $44 \mu \mathrm{g}$. As observed in Model 1, number of relapses per patient at baseline and cost of relapse management when increased by $20 \%$ of base-case results showed better ICERs $(\$ 23,824$ and $\$ 24,957$, respectively) compared with decreasing these inputs by $20 \%$ (ICERs $\$ 32,356$ and $\$ 25,596$, respectively).

\section{Discussion}

Results from Model 1, which evaluated the cost-effectiveness of PEG, indicated that PEG dominated IM IFN beta-la and GA. However, when compared with SC IFN beta-1b, PEG was more expensive and had comparable effectiveness, resulting in a high ICER (base case $\$ 1,978,000$ per relapse avoided). On the other hand, when compared with NAT, FIN, and DMF, PEG was less expensive and also less effective, showing that results are mixed for PEG as treatment for RRMS.

Results from Model 2, which evaluated the cost-effectiveness of ALT, indicated that ALT had a higher cost per patient $(\$ 162,591)$ but was more effective (relapse avoided 1.18) compared with IFN beta-la $44 \mu \mathrm{g}(\$ 144,392$; relapse avoided 0.46$)$. Thus, the average cost-effectiveness ratio for ALT ( $\$ 137,789$ per relapse avoided) was lower than IFN beta-la $44 \mu \mathrm{g}(\$ 313,896$ per relapse avoided). The ICER of ALT compared with IFN beta-la $44 \mu \mathrm{g}$ was $\$ 25,276$ per relapse avoided.

This study was conducted from a payer perspective, so only direct medical costs were included in the analysis. Also, since most payers prefer a shorter analytical time frame, relapses avoided was used as an outcome instead of quality-adjusted life-year (QALY), which seems to be a preferred outcome measure for a chronic condition with a longer analytical time frame. As previously discussed, our study results are consistent with the findings of other published studies that evaluated the cost-effectiveness of PEG and ALT.

In the U.S. study by Hernandez et al. (2016), ${ }^{8}$ PEG dominated IFN beta-la $44 \mu \mathrm{g}$ (cost savings of $\$ 22,070$ and additional 0.06 QALYs gained) and GA (cost savings of $\$ 19,163$ and 0.07 QALYs gained). In another U.S. study by Bozkaya et al., PEG dominated IFN beta-la $44 \mu \mathrm{g}$. Studies based in Ireland and Scotland by Hernandez et al. (both 2015) showed that-in comparison with IFN beta-la $22 \mu \mathrm{g}$, IFN beta-la $30 \mu \mathrm{g}$, IFN beta-la $44 \mu \mathrm{g}$, IFN beta-1b $250 \mu \mathrm{g}$, and GA-PEG treatment resulted in greater benefits and cost savings (Ireland) and greater benefits and cost savings compared with IFN beta-la 
$22 \mu \mathrm{g}$ and $30 \mu \mathrm{g}$, IFN beta-1b $250 \mu \mathrm{g}$, and ICERs of $£ 17,821$ and $£ 4,121$ when compared with GA and IFN beta-la $44 \mu \mathrm{g}$, respectively (Scotland). ${ }^{9} 10$ Study results from Iannazzo et al. (2015) in Italy show that PEG had ICERs of $€ 11,112$, €12,604, $€ 10,580, € 16,702$, and $€ 21,536$ per QALY when compared with IFN beta-la $30 \mu \mathrm{g}$, IFN beta-la $22 \mu \mathrm{g}$, IFN beta-1b $250 \mu \mathrm{g}$ (2 different suppliers), and GA, respectively, and dominated IFN beta-la $44 \mu \mathrm{g}$ (cost savings of $€ 21,456$ and 0.52 QALYs gained). ${ }^{11}$

For ALT, Kohn et al. (2013) conducted a U.S.-based study that had an ICER of $\$ 43,826$ per QALY compared with IFN beta-la $44 \mu \mathrm{g} .{ }^{14}$ Diaz et al. (2014) conducted a study in the United Kingdom and concluded that ALT dominated SC IFN beta-1b, FIN, and NAT and had a probabilistic and deterministic ICER of $£ 7,017$ per QALY and $£ 8,924$ per QALY, respectively, compared with GA. ${ }^{12}$ In the study by the National Center for Pharmacoeconomics in Ireland (2014), ALT had an ICER of $€ 4,166$ per QALY and dominated all other DMT comparators. ${ }^{13}$ Our study findings for ALT reflect findings from these studies when compared with IFN beta-la $44 \mu \mathrm{g}$.

\section{Limitations}

This study has several limitations that need to be considered. First, the models assumed $100 \%$ adherence to therapies, since adherence data for PEG and ALT were not available at the time of model development, and varied adherence rates were reported in the literature for different DMTs. ${ }^{42-45}$ Considering the lower dosing frequency for PEG compared with the DMTs in our model (except NAT), adherence to PEG can be expected to be higher. For ALT, dosing frequency was very low compared with IFN beta-la $44 \mu \mathrm{g}$.

Although ALT is associated with serious adverse effects, the low dosing frequency may lead to better adherence. Studies have reported adherence rates for DMTs, and a review by Menzin et al. (2013) showed that the overall adherence rate for IM IFN beta-la, SC IFN beta-1b, GA, and SC IFN beta-la ranged from $41 \%$ to $88 \%$ with a weighted mean adherence of $69.4 \%, 58.4 \%, 56.8 \%$, and $63.8 \%$, respectively. ${ }^{41}$ Bergvall et al. (2014) showed that adherence to FIN, any IFN therapy, GA, and NAT were $93.8 \%, 88.1 \%, 88.1 \%$, and $88.7 \%$, respectively. ${ }^{42}$ Polson et al. (2015) observed the adherence rate for fingolimod and dimethyl fumarate to be $82 \%$ and $77 \%$, respectively. ${ }^{43}$ Finally, a study by Hansen et al., conducted in Germany, reported the adherence rates for IM IFN beta-la, SC IFN beta-1b, SC IFN beta-1a, and GA to be $34.2 \%, 33.4 \%, 31.7 \%$, and $29.8 \%$, respectively, which was by far the lowest reported adherence rates. ${ }^{44}$

Second, there was no head-to-head clinical trial data in the PEG model, so pretreatment relapse rate was calculated based on the weighted average of relapse rates from the placebo groups from different phase 3 clinical trials of all DMTs. It is plausible that differences in study designs, procedures, or baseline characteristics may have an impact on these rates. However, the sensitivity analysis showed that the model was robust to the changes in the relapse rate input.

Third, univariate sensitivity analyses were conducted to test for uncertainty in model parameters. A multiway sensitivity might have shown an effect because of the combination of study variables but was not used, given the short study time horizon and small number of study variables.

Fourth, the outcome of interest was relapse avoided rather than sustained disability progression or other outcome such as QALY. Although relapse avoided is an important outcome, it did not fully represent the disease burden, since RRMS is a progressive disease. Because of the short analytic frame, relapse avoided was considered to be best suited for this study.

Finally, costs associated with adverse events were not included in the model, since these adverse events occurred over a longer period of time, which would not be captured in a short-term model. Earnshaw et al. (2009) estimated the cost of a 1-time PML treatment at $\$ 22,995$ (2007 U.S. dollars). ${ }^{45}$ Given the low incidence for PML, it was not expected to drastically affect the ICER. ${ }^{30,32,37}$ A cost-of-illness study by Saleh et al. (2009) estimated the annual cost of ITP treatment at around $\$ 7,000$ per person (year when cost was taken not specified). ${ }^{46}$ Also, the burden of AGBMD (reported as mean hospital costs) was estimated from national hospital discharge data and was around $\$ 47,405$ (2014 U.S. dollars). ${ }^{47}$ As with PML, the prevalence of these adverse events is very low and did not affect the ICERs in our short-term analyses. However, future long-term studies may need to capture the effect of these adverse events in order to see their effect on the DMT cost-effectiveness ratios.

\section{Conclusions}

In patients with RRMS, PEG dominated GA and IM IFN betala and had comparable effectiveness with SC IFN beta-lb but was more expensive. When compared with NAT, DMF, and FIN, PEG was less expensive but had lower effectiveness. Overall, PEG is a viable alternative compared with the DMTs in our model over a short-term horizon. The decision to choose PEG over other DMTs is influenced by multiple factors, including adverse event profile, ease of administration, clinical outcomes, and health plan coverage issues.

On the other hand, ALT is a cost-effective alternative when compared with SC IFN beta-la $44 \mu$ g over a short time horizon. ALT had an ICER of $\$ 25,276$ per relapse avoided 
compared with SC IFN beta-la $44 \mu$ g over a 2-year time horizon. However, caution should be exercised if the ICER is calculated over a longer time period, since serious adverse events associated with ALT may be a factor in influencing the overall cost. The results of this study will assist payers in making better decisions about choosing between PEG and ALT over a short-term horizon for patients with RRMS.

\section{Authors}

ANKUR A. DASHPUTRE, BPharm, and KHALID M. KAMAL, MPharm, PhD, Department of Pharmacy Administration, Mylan School of Pharmacy, Duquesne University, Pittsburgh, Pennsylvania. GAURI PAWAR, MD, Robert C. Byrd Health Sciences Center, West Virginia University, Morgantown.

AUTHOR CORRESPONDENCE: Khalid M. Kamal, MPharm, PhD, Department of Pharmacy Administration, 418 B Mellon Hall, Duquesne University, Mylan School of Pharmacy, 600 Forbes Ave., Pittsburgh PA 15282. Tel.: 412.396.1926; E-mail: kamalk@duq.edu.

\section{DISCLOSURES}

No outside funding supported this study. Kamal has received research funding from Novartis Pharmaceuticals and the College of Psychiatric and Neurologic Pharmacists and also serves as a consultant for the Lynx Group. Dashputre and Pawar report no conflicts of interest.

Study concept and design were primarily contributed by Dashputre, along with Kamal and Pawar. Dashputre took the lead in data collection, along with Kamal, and data analysis was performed by Dashputre, Kamal, and Pawar. The manuscript was written and revised primarily by Dashputre, along with Kamal and Pawar.

\section{REFERENCES}

1. Pietrangelo A, Higuera V. Multiple sclerosis by the numbers: facts, statistics, and you. March 24, 2015. Available at: http://www.healthline.com/ health/multiple-sclerosis/facts-statistics-infographic. Accessed April 29, 2017.

2. National Multiple Sclerosis Society. Health policy fact sheet \#2. Financial burdens for people with MS, their families, and society. Available at: http:// www.nationalmssociety.org/NationalMSSociety/media/MSNationalFiles/ Documents/Health-Policy-Fact-Sheet-2-Costs.pdf. Accessed April 29, 2017.

3. National Multiple Sclerosis Society. Types of MS. Available at: http://www. nationalmssociety.org/What-is-MS/Types-of-MS. Accessed April 29, 2017.

4. Calabresi PA, Kieseier BC, Arnold DL, et al. Pegylated interferon $\beta$-la for relapsing-remitting multiple sclerosis (ADVANCE): a randomised, phase 3, double-blind study. Lancet Neurol. 2014;13(7):657-65.

5. Cohen JA, Coles AJ, Arnold DL, et al. Alemtuzumab versus interferon $\beta$-la as first-line treatment for patients with relapsing-remitting multiple sclerosis: a randomized controlled phase 3 trial. Lancet. 2012;380(9856):1819-28.
6. Coles AJ, Twyman CL, Arnold DL, et al. Alemtuzumab for patients with relapsing multiple sclerosis after disease-modifying therapy: a randomised controlled phase 3 trial. Lancet. 2012;380(9856):1829-39.

7. Bozkaya D, Livingston TP, Migliaccio-Walle K, Mehta S, Odom T. The cost-effectiveness of disease modifying therapies for the treatment of relapsing-remitting multiple sclerosis. Value Health. 2015;8(3):A283 [Abstract]. Available at: http://www.valueinhealthjournal.com/article/S10983015(15)01710-6/fulltext. Accessed April 29, 2017.

8. Hernandez L, Guo S, Kinter E, Fay M. Cost-effectiveness analysis of peginterferon beta-la compared with interferon beta-la and glatiramer acetate in the treatment of relapsing-remitting multiple sclerosis in the United States. J Med Econ. 2016;19(7):684-95.

9. Hernandez L, Guo S, Toro-Diaz H, Carroll S, Syed Farooq SF. Costeffectiveness analysis of peginterferon beta-la in the treatment of relapsingremitting multiple sclerosis in Scotland. Value Health. 2015;18(7):A756 [Abstract]. Available at: http://www.valueinhealthjournal.com/article/S10983015(15)05014-7/fulltext. Accessed April 29, 2017.

10. Hernandez L, Guo S, Toro-Diaz H, Carroll S, Syed Farooq SF. Cost effectiveness analysis of peginterferon beta-la in the treatment of relapsingremitting multiple sclerosis in Ireland. Value Health. 2015;18(7):A756 [Abstract]. Available at: http://www.valueinhealthjournal.com/article/S10983015(15)04536-2/fulltext. Accessed April 29, 2017.

11. Iannazzo S, Santoni L, Saleri C, et al. Cost-effectiveness analysis of peginterferon beta-la in Italian relapsing remitting multiple sclerosis management. Value Health. 2015;18(7):A758 [Abstract]. Available at: http://www. valueinhealthjournal.com/article/S1098-3015(15)04548-9/fulltext. Accessed April 29, 2017.

12. Diaz RA, Doss S, Burke MJ, George E, Adler AI. Alemtuzumab for relapsing-remitting multiple sclerosis. Lancet Neurol. 2014;13(9):869-70. Available at: http://www.thelancet.com/journals/laneur/article/PIIS14744422(14)70184-X/fulltext?rss=yes. Accessed April 29, 2017.

13. National Centre for Pharmacoeconomics. Cost-effectiveness of alemtuzumab (Lemtrada) for the treatment of adult patients with relapsing remitting multiple sclerosis with active disease defined by clinical or imaging features. June 2014. Available at: http://docplayer.net/4459977-1-comparativeeffectiveness-of-alemtuzumab.html. Accessed April 29, 2017.

14. Kohn CG, Costales V, Coleman CI, Young D, Limone BC. Costeffectiveness of alemtuzumab for relapsing-remitting multiple sclerosis. Presented at: Consortium of Multiple Sclerosis Centers Fifth Cooperative Meeting; May 29-June 1, 2013; Orlando, FL. Available at: https://cmsc.confex.com/cmsc/2013/webprogram/Paper1810.html. Accessed April 29, 2017.

15. Goldberg LD, Edwards NC, Fincher C, Doan QV, Al-Sabbagh A, Meletiche DM. Comparing the cost-effectiveness of disease-modifying drugs for the first-line treatment of relapsing-remitting multiple sclerosis.

J Manag Care Pharm. 2009;15(7):543-55. Available at: http://www.jmcp.org/ doi/10.18553/jmcp.2009.15.7.543.

16. Jacobs LD, Cookfair DL, Rudick RA, et al. Intramuscular interferon beta-la for disease progression in relapsing multiple sclerosis. The Multiple Sclerosis Collaborative Research Group (MSCRG). Ann Neurol. 1996;39(3):285-94. 
17. The IFNB Multiple Sclerosis Study Group. Interferon beta-lb is effective in relapsing-remitting multiple sclerosis. I. Clinical results of a multicenter, randomized, double-blind, placebo-controlled trial. Neurology. 1993;43(4):655-61.

18. Johnson KP, Brooks BR, Cohen JA, et al. Copolymer 1 reduces relapse rate and improves disability in relapsing-remitting multiple sclerosis: results of a phase III multicenter, double-blind placebo-controlled trial. The Copolymer 1 Multiple Sclerosis Study Group. Neurology. 1995;45(7):1268-76.

19. Kappos L, Radue E, O'Connor P, et al. A placebo-controlled trial of oral fingolimod in relapsing multiple sclerosis. N Engl J Med. 2010;362(5):387-401.

20. Polman $\mathrm{CH}$, O'Connor PW, Havrdova E, et al. A randomized, placebocontrolled trial of natalizumab for relapsing multiple sclerosis. N Engl J Med. 2006;354(9):899-910.

21. Gold R, Kappos L, Arnold DL, et al. Placebo-controlled phase 3 study of oral BG-12 for relapsing multiple sclerosis. N Engl J Med. 2012;367(12):1098-107.

22. Randomised double-blind placebo-controlled study of interferon beta-la in relapsing/remitting multiple sclerosis. PRISMS (Prevention of Relapses and Disability by Interferon beta-la Subcutaneously in Multiple Sclerosis) Study Group. Lancet. 1998;352(9139):1498-504.

23. Kobelt G, Berg J, Lindgren P, Jonsson B, Stawiarz L, Hillert J. Modeling the cost-effectiveness of a new treatment for MS (natalizumab) compared with current standard practice in Sweden. Mult Scler. 2008;14(5):679-90.

24. Bell C, Graham J, Earnshaw S, Oleen-Burkey M, Castelli-Haley J, Johnson K. Cost-effectiveness of four immunomodulatory therapies for relapsing-remitting multiple sclerosis: a Markov model based on long-term clinical data. J Manag Care Pharm. 2007;13(3):245-61. Available at: http:// www.jmcp.org/doi/10.18553/jmcp.2007.13.3.245.

25. Chiao E, Meyer K. Cost effectiveness and budget impact of natalizumab in patients with relapsing multiple sclerosis. Curr Med Res Opin. 2009;25(6):1445-54.

26. Plegridy (peginterferon beta-la) injection, for subcutaneous injection. Biogen Idec. Revised October 2015. Available at: https://www.plegridy.com/ pdfs/plegridy-prescribing-information.pdf. Accessed April 29, 2017.

27. Avonex (interferon beta-la) injection, for intramuscular injection. Biogen Idec. Revised March 2016. Available at: http://www.avonex.com/pdfs/ Avonex_Prescribing_Information.pdf. Accessed April 29, 2017.

28. Betaseron (interferon beta-1b) for injection, for subcutaneous use. Bayer HealthCare Pharmaceuticals. Revised April 2016. Available at: http://labeling.bayerhealthcare.com/html/products/pi/Betaseron_PI.pdf. Accessed April 29, 2017.

29. Copaxone (glatiramer acetate injection) for subcutaneous use. Teva Neuroscience. Revised August 2016. Available at: https://www.copaxone. com/Resources/pdfs/PrescribingInformation.pdf. Accessed April 29, 2017.

30. Gilenya (fingolimod) capsules, for oral use. Novartis Pharma Stein AG. Revised February 2016. Available at: http://www.pharma.us.novartis.com/ product/pi/pdf/gilenya.pdf. Accessed April 29, 2017.

31. Tysabri (natalizumab) injection, for intravenous use. Biogen Idec. Revised May 2016. Available at: http://www.tysabri.com/prescribingInfo. Accessed April 29, 2017.
32. Tecfidera (dimethyl fumarate) delayed-release capsules, for oral use. Biogen Idec. Revised January 2017. Available at: http://www.tecfidera.com/ pdfs/full-prescribing-information.pdf. Accessed April 29, 2017.

33. Asche CV, Singer ME, Jhaveri M, Chung H, Miller A. All-cause health care utilization and costs associated with newly diagnosed multiple sclerosis in the United States. J Manag Care Pharm. 2010;16(9):703-12. Available at http://www.jmcp.org/doi/10.18553/jmcp.2010.16.9.703.

34. Lemtrada (alemtuzumab) injection, for intravenous use. Genzyme. Revised July 2016. Available at: http://products.sanofi.us/lemtrada/lemtrada. pdf. Accessed April 29, 2017.

35. Rebif (interferon beta-la), for subcutaneous injection. EMD Serono, Revised November 2015. Available at: http://www.emdserono.com/ ms.country.us/en/images/Rebif_PI_tcm115_140051.pdf?Version. Accessed April 29, 2017.

36. U.S. Food and Drug Administration. Approved risk evaluation and mitigation strategies (REMS). Available at: https://www.accessdata.fda.gov/ scripts/cder/rems/index.cfm?event=IndvRemsDetails.page\&REMS=340. Accessed April 29, 2017.

37. Yousry TA, Major EO, Ryschkewitsch, et al. Evaluation of patients treated with natalizumab for progressive multifocal leukoencephalopathy. N Engl J Med. 2006;354(9):924-33.

38. Centers for Medicare \& Medicaid Services. 2015 physician fee schedule. Available at: https://www.cms.gov/apps/physician-fee-schedule/search/ search-results.aspx? $Y=0 \& \mathrm{~T}=0 \& H \mathrm{H}=0 \& C \mathrm{~T}=3 \& H \mathrm{H}=96360 \& \mathrm{M}=5$. Accessed April 29, 2017.

39. U.S. Bureau of Labor Statistics. Occupational employment and wages. May 2016. Available at: http://www.bls.gov/oes/current/oes291069.htm. Accessed April 29, 2017.

40. U.S. Bureau of Labor Statistics. Consumer Price Index. All urban consumers. Available at: http://data.bls.gov/timeseries/CUUR0000SAM?output_ view=pct_12mths. Accessed April 29, 2017.

41. Menzin J, Caon C, Nichols C, White LA, Friedman M, Pill MW. Narrative review of the literature on adherence to disease-modifying therapies among patients with multiple sclerosis. J Manag Care Pharm. 2013;19 (1 Suppl A):S24-40. Available at: http://www.jmcp.org/doi/abs/10.18553/ jmcp.2013.19.s1.S24.

42. Bergvall N, Petrilla AA, Karkare SU, et al. Persistence with and adherence to fingolimod compared with other disease-modifying therapies for the treatment of multiple sclerosis: a retrospective U.S. claims database analysis. J Med Econ. 2014;17(10):696-707.

43. Polson M, Ko J, Lord TC, Evangelatos T, Herrera V. Real-world comparison of patient adherence and persistence to fingolimod vs. dimethyl fumarate in multiple sclerosis. Presented at: Academy of Managed Care Pharmacy Nexus, October 2015; Orlando, FL. Available at: https://wwwl.magellanrx. com/media/330251/fingolimod-vs-dimethyl-fumarate-poster_2015-fallamcp.pdf. Accessed April 29, 2017.

44. Hansen K, Schüssel K, Kieble M, et al. Adherence to disease modifying drugs among patients with multiple sclerosis in Germany: a retrospective cohort study. PLoS One. 2015;10(7):e0133279. 
45. Earnshaw SR, Graham J, Oleen-Burkey M, Castelli-Haley J, Johnson K. Cost effectiveness of glatiramer acetate and natalizumab in relapsing-remitting multiple sclerosis. Appl Health Econ Health Policy. 2009;7(2):91-108.

46. Saleh MN, Fisher M, Grotzinger KM. Analysis of the impact and burden of illness of adult chronic ITP in the U.S. Curr Med Res Opin. 2009;25(12):2961-69.
47. Agency for Healthcare Research and Quality. HCUPnet. Healthcare Cost and Utilization Project. 2014 National Inpatient Sample. Hospitalization cost for Goodpasture's Syndrome. December 9, 2016. Available at: https://www. hcup-us.ahrq.gov/databases.jsp. Accessed April 29, 2017. 